ISSN 0258-7122 (Print), 2408-8293 (Online)

Bangladesh J. Agril. Res. 41(3): 471-480, September 2016

\title{
EVALUATION OF SOME ADDITIVES FOR ACCEPTABILITY WITH ZINC PHOSPHIDE BAIT AGAINST RODENT
}

\author{
M. S. $\operatorname{ALAM}^{1}$ AND A. T. M. HASANUZZAMAN ${ }^{2}$
}

\begin{abstract}
Laboratory and field study were conducted to evaluate the effects of some bait additives namely molasses, sugar, dry fish and powder milk mixed with wheat flour to increase the acceptability of additives mixed bait and the efficiency of poison bait. The findings showed that the additives mixed plain bait led to an increase the palatability and consumption rate. The most accepted plain bait for rodent was the bait combination molasses + wheat flour followed by sugar + wheat flour. The highest mortality was observed from the bait in the treatment combination powder milk + dry fish + wheat flour $+\mathrm{Zn}_{3} \mathrm{P}_{2}(90 \%)$ followed by (powder milk + molasses + dry fish + wheat flour $\left.+\mathrm{Zn}_{3} \mathrm{P}_{2}\right)(80 \%)$ in laboratory. The average zinc phosphide bait consumption was highest in the treatment dry fish + wheat flour $+\mathrm{Zn}_{3} \mathrm{P}_{2}(1.56 \mathrm{~g} / \mathrm{rat} /$ day $)$ followed by molasses + dry fish + powder milk + wheat flour $+\mathrm{Zn}_{3} \mathrm{P}_{2}(0.80 \mathrm{~g} / \mathrm{rat} /$ day $)$. All these additives mixed with zinc phosphide increase the consumption rate and the efficacy of bait. In field trial the higher population reduction (76-86\%) was achieved from the bait dry fish + wheat flour $+\mathrm{Zn}_{3} \mathrm{P}_{2}$ followed by dry fish + powder milk + wheat flour $+\mathrm{Zn}_{3} \mathrm{P}_{2}(76-80 \%)$ and the lowest in powder milk + wheat flour $+\mathrm{Zn}_{3} \mathrm{P}_{2}(30 \%)$ All these additives mixed with zinc phosphide increased the consumption rate and the efficacy of poison bait.
\end{abstract}

Keywords: Additives, acceptability, consumption, zinc phosphide, rat.

\section{Introduction}

Rodents constitute the largest order of the existing mammals. They are the most destructive vertebrate pest of the agriculture products (Barnett and Prakash, 1975). Rodent damage buildings, household's good, electrical wire, irrigation channel etc. and they are also involved in the transmission of numerous human diseases (WHO, 1974). Mainly three to four species of rats cause damage to crops among them lesser bandicoot rat Bandicota bengalensis is the pre dominant species in Bangladesh. Zinc phosphide bait, snap trap and live traps are most commonly used in Bangladesh to minimize the losses. Zinc phosphide is reported to be an effective acute rodenticide. Numerous researchers have reported bait acceptance problems due to bait shyness related to bitter taste or sub-lethal illness and subsequent conditioned aversion (Prakash and Ghosh, 1992, Reidinger,

\footnotetext{
${ }^{1 \& 2}$ Senior Scientific Officer, Vertebrate Pest Division, Bangladesh Agricultural Research Institute (BARI), Joydebpur, Gazipur-1701, Bangladesh.
} 
1995). Effect of bait shyness may persist more than a year even zinc phosphide removed from the bait.

Bait shyness problems may be over come by using attracting palatable bait. Some studies have been performed to upgrade the present rodent control tactics to make it more efficient through mixing different locally available palatable food or bait additives (Pervez et al., 2005; Johnston et al., 2005; Naeem et al., 2011). ElGawad and Ali (1982 a) improved the efficiency of zinc phosphide bait by adding molasses to crushed maize bait. EI-Rahmen (1991) studied the effect of some aromatic plants on the palatably of crushed maize. Asran (1993) enhanced bait consumption by adding sesame oil to crushed maize. Abdel-Rehman (1999) increase zinc phosphide consumption by adding powder milk, bone meal, fishmeal with crushed maize.

The present study was aimed to investigate the palatability and consumption of additives mixed zinc phosphide bait and the efficacy of poison $\left(\mathrm{Zn}_{3} \mathrm{P}_{2}\right)$ bait by adding different additives such as molasses, sugar, dry fish and powder milk mixed with wheat flour in the laboratory and field condition.

\section{Materials and Method}

The study was carried out during 2012 and 2013 in the field and the laboratory of Vertebrate Pest Division, Bangladesh Agricultural Research Institute, Gazipur. Lesser bandicoot rat, Bandicota bengalensis was used as test animal. The animals were kept under the laboratory condition at least one week for acclimatization before starting the experiment. All the animals were starved for 6 hours before applying the treatments.

\section{Observation of food consumption}

All the baits were compared with standard bait (wheat grain). For each treatment 10 rats ( 5 males \& 5 females) were used and they were individually caged. For all testing method $20 \mathrm{~g}$ of bait was provided in individual food cups and consumption rate was recorded to the nearest $g$ on a daily basis for each rat to each food type presented. Paper was placed under each cage to recover spilled grain and to ensure accurate measurements of consumption. Daily food intake was determined by subtracting the spilled grain and the food remaining in the cup from the quantity originally given to each rat.

\section{Preparation of zinc phosphide baits with different additives}

For preparing $2 \%$ zinc phosphide bait with different additives, following combination of the ingredients were used such as powder milk (7.5\%), sugar $(20 \%)$, molasses $(20 \%)$ dry fish $(10 \%)$ mixed with wheat flour. The treatment combinations are - 
$\mathrm{T}_{1}=$ Molasses + dry fish + powder milk + wheat flour, $\mathrm{T}_{2}=$ Sugar + dry fish + powder milk + wheat flour, $\mathrm{T}_{3}=$ Dry fish + powder milk + wheat flour, $\mathrm{T}_{4}=$ Molasses + dry fish + wheat flour, $\mathrm{T}_{5}=$ Molasses + powder milk + wheat flour, $\mathrm{T}_{6}=$ Molasses + wheat flour $\mathrm{T}_{7}=$ Powder milk + wheat flour, $\mathrm{T}_{8}=$ Dry fish + wheat flour, $\mathrm{T}_{9}=$ Sugar + wheat flour

\section{Laboratory efficacy test}

All the baits were compared with standard plain bait (wheat grain). The feeding test was conducted in the laboratory using acclimatized ten adults rats for each treatment. Two cups of bait were offered to each rat, one cup containing $20 \mathrm{~g}$ of plain wheat grain and another cup containing $20 \mathrm{~g}$ additive mixed $\mathrm{Zn}_{3} \mathrm{P}_{2}$ bait. The poison bait was supplied for three consecutive days and the plain wheat grains were provided up to the end of the experiment. Spilled bait material or wheat grains were collected in a paper placed beneath the cage and weighed for both the cups. Water was supplied at ad libitum. Consumption of bait additive, plain bait, mortality, and baits acceptance of the rats was recorded everyday. Tested bait acceptance was calculated using the EPPO (1982) modification equation.

Tested bait acceptance $(\%)=\frac{\text { Tested bait uptake }(\mathrm{g})}{\text { Tested bait uptake }(\mathrm{g})+\operatorname{Standard} \text { bait uptake }(\mathrm{g})} \times 100$

\section{Field Efficacy test}

The experiments were carried out at farmer's wheat fields in two different areas at Dinajpur and Rajshahi district of Bangladesh. In all the locations clear signs of rodent infestation were detected. Additive mix $2 \%$ zinc phosphide $\left(\mathrm{Zn}_{3} \mathrm{P}_{2}\right)$ was used for this experiment. However, in the field test top ranking first six combinations along with wheat flour mixed with zinc phosphide were selected for the next test.

So, The treatments combination are:

$\mathrm{T}_{1}=$ Molasses + dry fish + powder milk + wheat flour $+\mathrm{Zn}_{3} \mathrm{P}_{2}, \mathrm{~T}_{2}=$ Dry fish + powder milk + wheat flour $+\mathrm{Zn}_{3} \mathrm{P}_{2}, \mathrm{~T}_{3}=$ Molasses + dry fish + wheat flour + $\mathrm{Zn}_{3} \mathrm{P}_{2}, \mathrm{~T}_{4}=$ Powder milk + wheat flour $+\mathrm{Zn}_{3} \mathrm{P}_{2}, \mathrm{~T}_{5}=$ Dry fish + wheat flour + $\mathrm{Zn}_{3} \mathrm{P}_{2}, \mathrm{~T}_{6}=$ Plain wheat $+\mathrm{Zn}_{3} \mathrm{P}_{2}$ (Standard poison bait)

Two methods were namely, the active burrow count method (El-Gawad and Ali $1982 \mathrm{~b}$ ) and the foot tracks activity (using tracking tile) method (El-Sherbiny and Awad, 1987) were used to determine the population density in each location. Twenty active burrows/spots were used for each treatment. Before applying treatment all the active burrows were identified properly. Twenty tracking tiles $(20 \times 20 \mathrm{~cm})$ for foot tact activity were used for each treatment. Foot tracts 
activity were taken for two nights for both pre and post treatment operation. The pre and post treatment rodent population were determined by using both of this method.

Additives mixed zinc phosphide $10 \mathrm{~g}$ bait was placed near the burrow opening on a piece of paper. Bait was given in the evening and was collected in the next morning. Bait was placed for consecutive three days. Each treatment was replicated in three places in each location. Consumption was recorded everyday. Efficacy of the treatment was judged on the basis of rodent activity and percent reduction in population was calculated.

\section{Data analysis}

Daily consumption of each combination of additives mix diet was converted to gram. Additives mixed plain bait uptake was compare with Student t-test. The means with standard error were also calculated. Field data were analysis by one way analysis of variance and means were separated by LSD at $0.05 \%$ probability level. In all statistical test percentage data were transformed to arcsine to stabilize variance. STAR software version 2.0.1 (2014) was used to analyze the data.

\section{Results and Discussion}

Palatability and consumption of different additives mixed plain bait

The rat consumed a significantly greater amount of additives mixed plain bait than the plain wheat grain bait. Table 1 revealed that molasses mixed with wheat flour was the most accepted bait, followed by molasses mixed with dry fish and wheat flour and the less acceptable bait was powder milk mixed with wheat flour. Bait acceptance was arranged descending order as follows: $79.15 \%$ for molasses + wheat flour $>78.07 \%$ for molasses + dry fish + wheat flour $>77.86 \%$ for Sugar + wheat flour $>71.41 \%$ for molasses + dry fish + powder milk + wheat flour $>63.36 \%$ for dry fish + wheat flour $>61.80 \%$ for sugar + dry fish + powder milk + wheat flour $>50.40 \%$ for dry fish + powder milk +wheat flour $>45.95 \%$ for powder milk + wheat flour $>45.36 \%$ for molasses + powder milk + wheat flour. It is obvious from the results that by adding additives enhanced the consumption and acceptance of bait for $B$. bengalensis.

The obtained results urged us to investigate the effect of the tested additives on the acceptance of $B$. bengalensis to $2 \%$ zinc phosphide bait loaded on wheat flour as an attempt to overcome the bait shyness phenomenon and increase the reduction of rodent population as a primary step before using other control measurements such as anticoagulant rodenticides. 


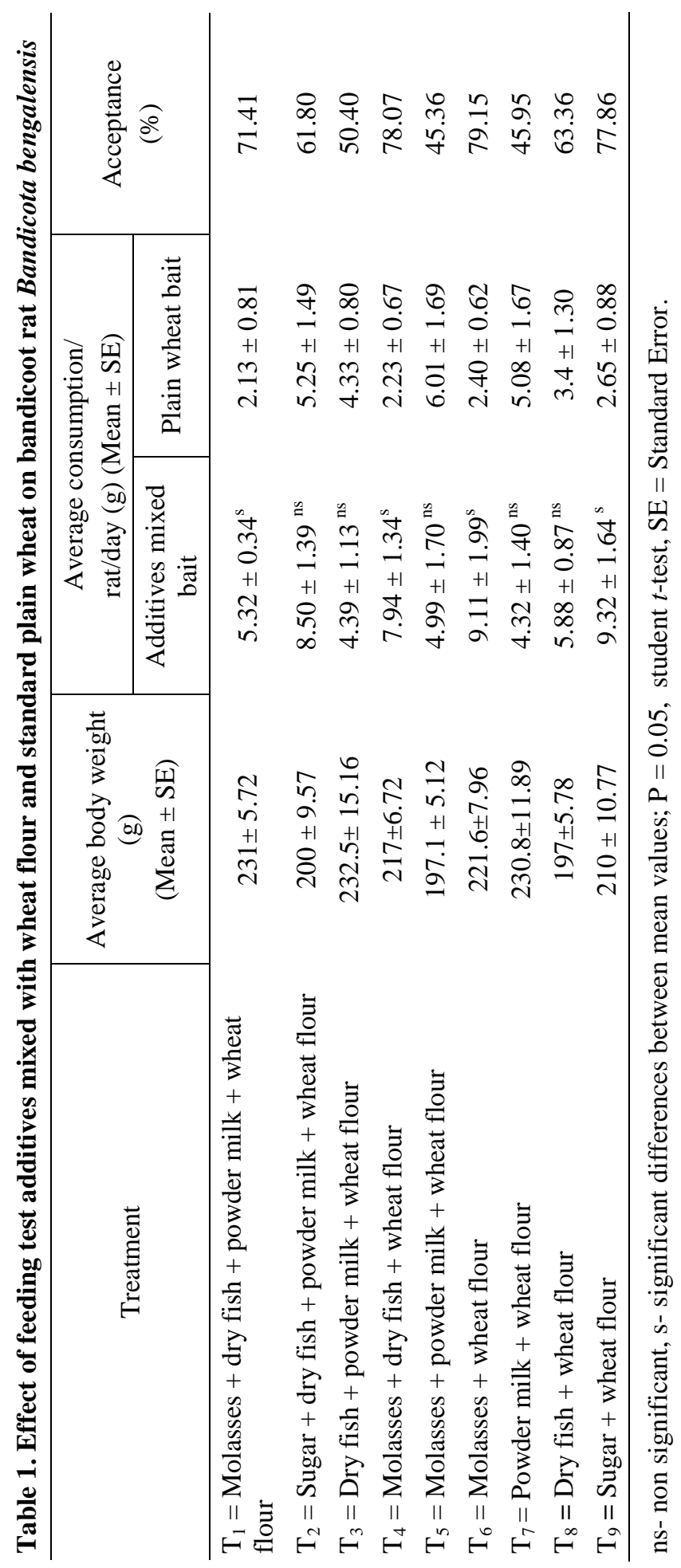


The effects of different additives mixed with zinc phosphide poison bait in the laboratory are presented in Table 2 . It revealed that adding different additives mixed with Zinc Phosphide bait increased the efficacy of bait. The highest mortality $(90 \%)$ was observed from the treatment combination where zinc phosphide was mixed with dry fish powder milk and wheat flour followed by molasses + dry fish + powder milk + wheat flour $+\mathrm{Zn}_{3} \mathrm{P}_{2}$, and molasses + dry fish + wheat flour $+\mathrm{Zn}_{3} \mathrm{P}_{2}$ respectively. The lowest mortality (30\%) was observed from the treatment combination where zinc phosphide was mixed with sugar + dry fish + powder milk + wheat flour, molasses + powder milk + wheat flour and molasses + wheat flour, respectively.

The highest zinc phosphide poison bait consumption (1.56 g/rat/day) was recorded from the treatment combination dry fish + wheat flour) followed by molasses + dry fish + powder milk + wheat flour $(0.80 \mathrm{~g} / \mathrm{rat} /$ day $)$. The lowest poison bait consumption $(0.14 \mathrm{~g} / \mathrm{rat} / \mathrm{day})$ was observed from the the treatment combination sugar + wheat flour.

The most accepted (33.21\%) poison bait for B. bengalensis was the treatment combination molasses + dry fish + powder milk + wheat flour $+\mathrm{Zn}_{3} \mathrm{P}_{2}$ followed by dry fish + wheat flour $+\mathrm{Zn}_{3} \mathrm{P}_{2}(29.24 \%)$ (Table 2$)$. The acceptability of the poison baits in descending order were $33.21 \%$ for molasses + dry fish + powder milk + wheat flour $)>29.24 \%$ for dry fish + wheat flour $>25.64 \%$ for dry fish + powder milk + wheat flour $>21.30 \%$ for (powder milk + wheat flour $>17.34 \%$ for molasses + dry fish + wheat flour $>17.26 \%$ for plain wheat $+\mathrm{Zn}_{3} \mathrm{P}_{2}$.

Table 3 revealed that the total consumption of additives mixed poison bait differed significantly among the treatments. The highest poison bait consumption was recorded from the treatment combination dry fish + wheat flour $+\mathrm{Zn}_{3} \mathrm{P}_{2}$ (144g and $182.7 \mathrm{~g}$ ) in both the location at Dinajpur and Rajshahi and the lowest consumption was recorded in molasses + powder milk + wheat flour $+\mathrm{Zn}_{3} \mathrm{P}_{2}$ $(50.91 \mathrm{~g})$ at Dinajpur and Powder milk + wheat flour $+\mathrm{Zn}_{3} \mathrm{P}_{2}(48.69 \mathrm{~g})$ at Rajshahi. The daily consumption/spot (g) of additive mixed poison bait was followed the same trend as total consumption and significantly different among the treatments.

The efficacy of different additives mixed with zinc phosphide poison bait is presented in table 4 and 5 . The highest population reduction of rat was achieved from the treatment combination of zinc phosphide mixed with dry fish + wheat flour $(76-86 \%)$ and dry fish + powder milk + wheat flour (76-80\%) in both the location. The lowest population reduction was observed in the treatment combination zinc phosphide mixed with powder milk and wheat flour $(30 \%)$ in both the location. 


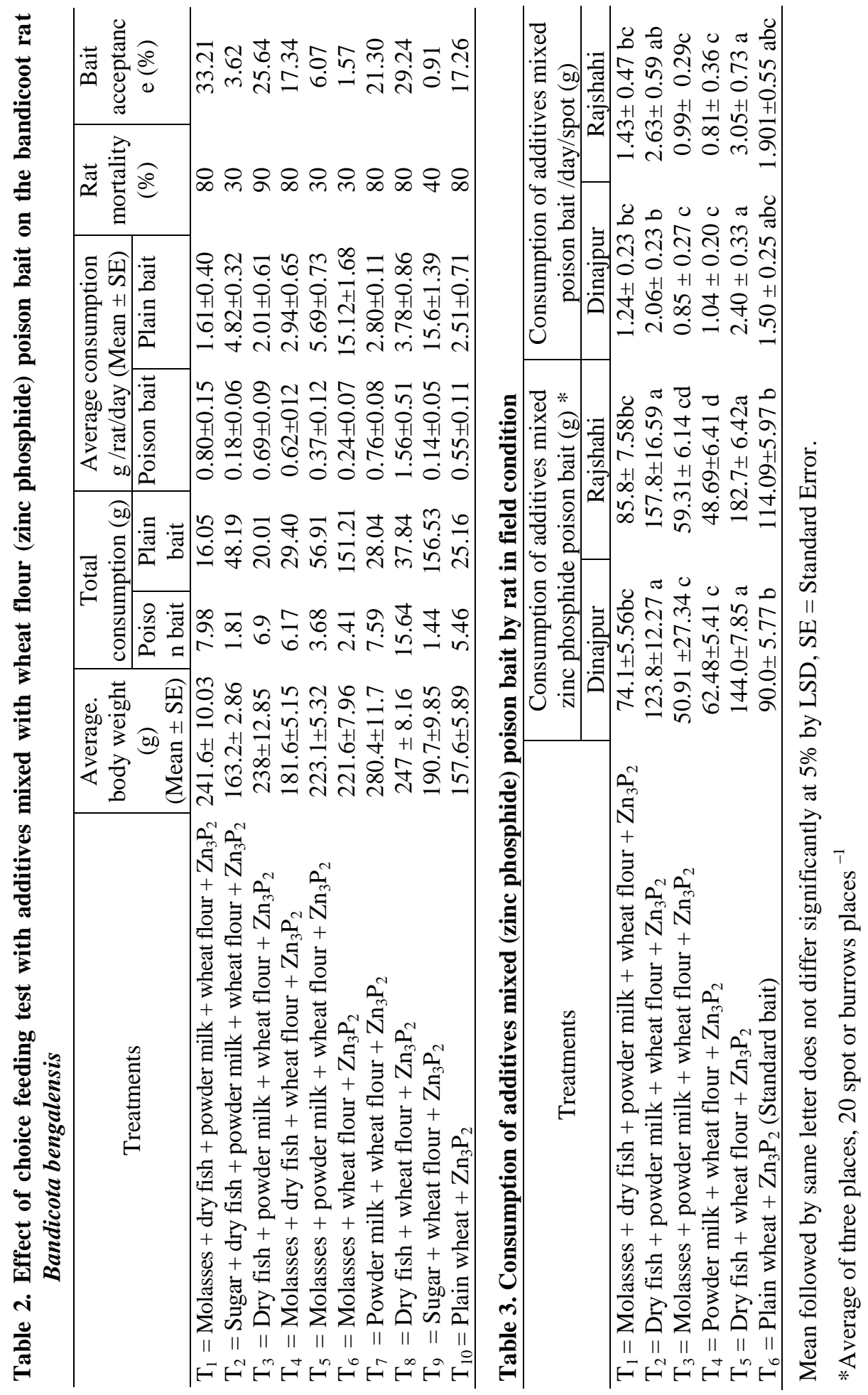




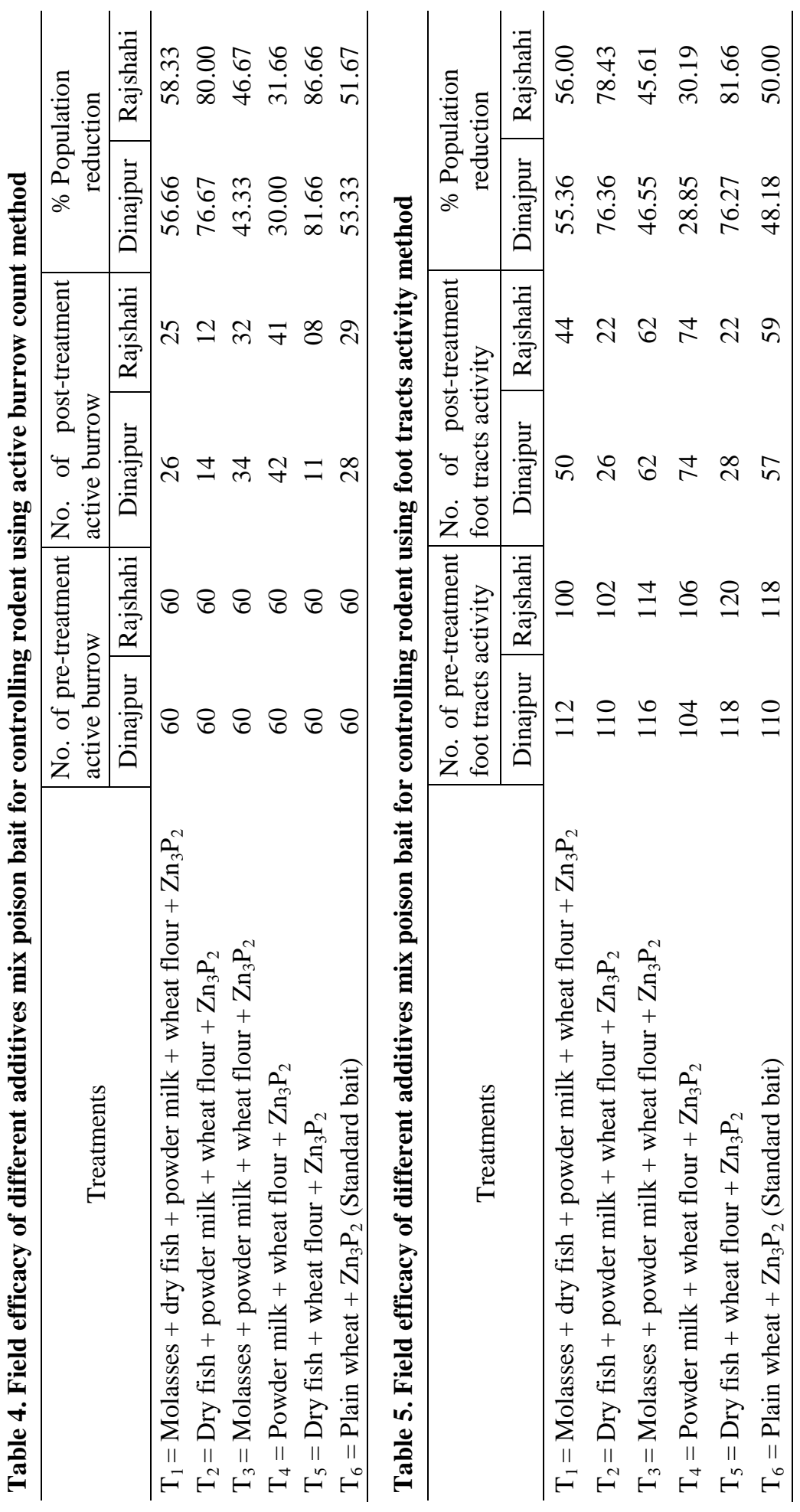


The results of this study are supported by Parasad et al. (1985) who found that rodents consumed significantly less poison baits than the plain alternative. In wet condition pungent effect of zinc phosphide increased which increased the bait shyness problem in rat. Molasses probably may absorbed moisture in the open field which increased the pungency of zinc phosphide and it is one of the causes for lower consumption of zinc phosphide poison bait. Behavioral change may play an important role in formulating attractive bait. Increase in bait consumption depends on addition of different additives (Naeem et al., 2011). By adding sugar (glucose or sucrose) with bait increase the acceptability and palatability of cereal bait (Smith and Wilson, 1989). Use of $2 \%$ butter oil greatly enhance intake of cracked millet and this combination would yield significant control of $B$. bengalensis used as poison bait (Naeem et al., 2011). EI-Gawad and Ali (1982 a) enhanced the acceptance of crushed maize bait to rodent species by adding sucrose and molasses. Abdel-Rahmen (1999) increased acceptability of zinc phosphide by adding powder milk, fishmeal and blood meal to crushed maize against house mouse, Mus musculus. Additives added bait improve poison bait acceptance to the lesser bandicoot rat, Bandicota bengalensis and egg mixed zinc phosphide bait has more potential in enhancing bait acceptance of zinc phosphide against field rodents of Sindh, Pakistan (Pervez et al., 2005).

\section{Conclusion}

The findings of the present study revealed that significant control of field rats in wheat might be achieved and the usage of dry fish (fish meal) based additive mix of zinc phosphide bait may be suggested for high consumption rate. However, the present findings indicate that adding additives with bait can increase bait consumption and increase the efficacy of zinc phosphide bait.

\section{References}

Abdel-Rahman, A. 1999. Effect of certain additives to zinc phosphide crushed maize bait against the house mouse, Mus musculus. Egypt. J. Agric. Res. 77(2):1147-1153.

Asran, A. 1993. Effect of some additives on food consumption of the house mouse, Mus musculus in a new reclaimed area. Egypt. J. Agric Res. 71(4): 901-906.

Barnett, S.A. and I. Prakash. 1975. Rodents of economic importance in India, Pp.1-175. New Delhi and London: Arnold-Heinemann.

El-Gawad, A.K. and A.M. Ali. 1982a. On the preparation of zinc phosphide as rodent control bait. Assiut J. Agric. Sci. 13(2): 131-135.

El-Gawad, K.A. and A.M. ALI. 1982 b. The active burrow as a parameter for detection of population density of rodents during rat control campaign. Assiut J. Agric. Sci. 13(2):211-215.

El-Rahman, A.A. 1991. Effect of certain aromatic plants on the acceptance of maize baits by the house mouse Mus musculus. Egypt. J. Agric Res. 69(1): 269-272. 
El-Sherbiny, A.A. and A.M. Awad. 1987. Field evaluation of the relative efficacy of two rodenticides. Egypt. J. wildlife and Natural Resources. 9: 69-80.

EPPO. 1982. Guideline for the biological evaluation of rodenticides. No 1: laboratory tests for the evaluation of the toxicity and acceptability of rodenticides and rodenticide preparations. European and Mediterranean Plant Protection Organization, Paris.

Johnston, J.J., D.L. Nolte, B.A. Kimball, K.R. Perry and J.C. Hurley. 2005. Increasing acceptance and efficacy of zinc phosphide rodenticide baits via modification of the carbohydrate profile. Crop Protection 24:381-385.

Naeem, M., I. Ahmed, I. Hussain and M.S. Ahmed. 2011. Performance of taste enhancers mixed with cereal bases and evaluation of the most prefered bait composition for Bandicota bengalensis (Gray). African J. Biotech. 10(19): 3938-3944,

Parshad, V.R., N. Ahmad and G. Chopra. 1985. Laboratory and field evaluation of brodifacoum for rodent control. Int. Biodeterioration 21(2):107-112.

Pervez, A., S.M. Ahmed, A.A. Khan and S.B. Lathiya. 2005. Comparative field efficacy of some additive formulated baits against rodent pests of wheat crop in Sindh, Pakistan Pakistan J. Zool. 37(4):269-274.

Prakash, I, and P. Ghosh (editors). 1992. Rodents in Indian Agriculture, Vol.2, Scientific Publishers, Jodhpur, India.

Redinger, R.F.Jr.1995. Recent studies on flavor aversion learning in wildlife damage management. Pages 101 -120 In: J. R. Mason. Editor. Repellents in Wildlife Management: Proceedings. Colorado State University: Fort Collins, Colorado, USA.

Smith, C.S. and L.S. Wilson. 1989. Study of a lifetime of sucrose intake by the fisher-344 rat. Ann. New York Acad. Sci. 561: 291-306.

WHO. 1974. Ecology and control of rodents of public health importance. WHO Technical Report, Series No. 553:1-2. 